\title{
The Image of the Babel Tower in Contemporary Art and a Parallel Disruption of the Statue of Liberty
}

\author{
Dr Ayfer Karabıyı \\ Gastprofessur | Theorie \& Praxis der Visuellen Kommunikation - \\ Kunsthochschule Kassel
}

\begin{abstract}
The 'Legend of the Babel Tower' is mentioned in local narratives in many regions of the world and in mainstream religions, and is a subject much worked on in the field of art. This study will focus on the theme of the Babel Tower myth as discussed in contemporary art. The intention here is to discuss the reasons for the different assessments of the Babel myth in each period.
\end{abstract}

\section{Keywords}

Babel Tower - contemporary art - language - Statue of Liberty

The 'Legend of the Babel Tower' is a work that has been much studied in the field of art. This legend can be described briefly as follows:

Babel, or Babylon was the name of the capital of the Chaldeans that was built on the shore of the Firat River in the $17^{\text {th }}$ century B.C. According to mythology, the Tower of Chaos, or Zikkurat Etemenanki, arose in this city of Babylon. The Tower was the home of people speaking many languages. They could live together and negotiate, because the presence of the Tower created a common language for them. According to the myth,

* This work is devised from Associate Prof. Şive Neşe Baydar's lecture notes entitled 'How can an idea be improved based on the image of the tower?'

** Theorie \& Praxis der Visuellen Kommunikation - Kunsthochschule Kassel, ayferkrbk @gmail.com.

(C) KARABIYIK, 2018 | DOI 10.1163/25430149-00101001

This is an open access article distributed under the terms of the prevailing CC-BY-NC license at the time of publication. 
this awakened God's anger. The Tower was torn down, and its inhabitants were scattered all over the world.

BAŞ, 2005

Now, each nation has a different language and lives in a different place, so it is no longer possible to communicate. Nations need a common knowledge in order to reconnect. Perhaps it is art that is charged with overcoming the language disorder and cultural difference that has existed since the Babylonian legacy. The destruction of the edifice that built towards the sky to reach God has also opened up another form of existence that spreads horizontally. Nation states are one of the consequences of the disintegration of the tongues. As a conceptual myth, many different readings of the Babel Tower can thus be performed, both semiologically and semantically. The article will trace and compare a select sample of Babel Tower interpretations in contemporary art, to demonstrate how the structure has been read in different ways through different evaluations of the Babylonian myth.

The Monument to the Third International, also known as 'Tatlin's Tower' (Images 1 and 2), was designed by Vladimir Tatlin, a pioneer of Constructivism. In its striking design, the monument consists of a curved, spiral iron cage,
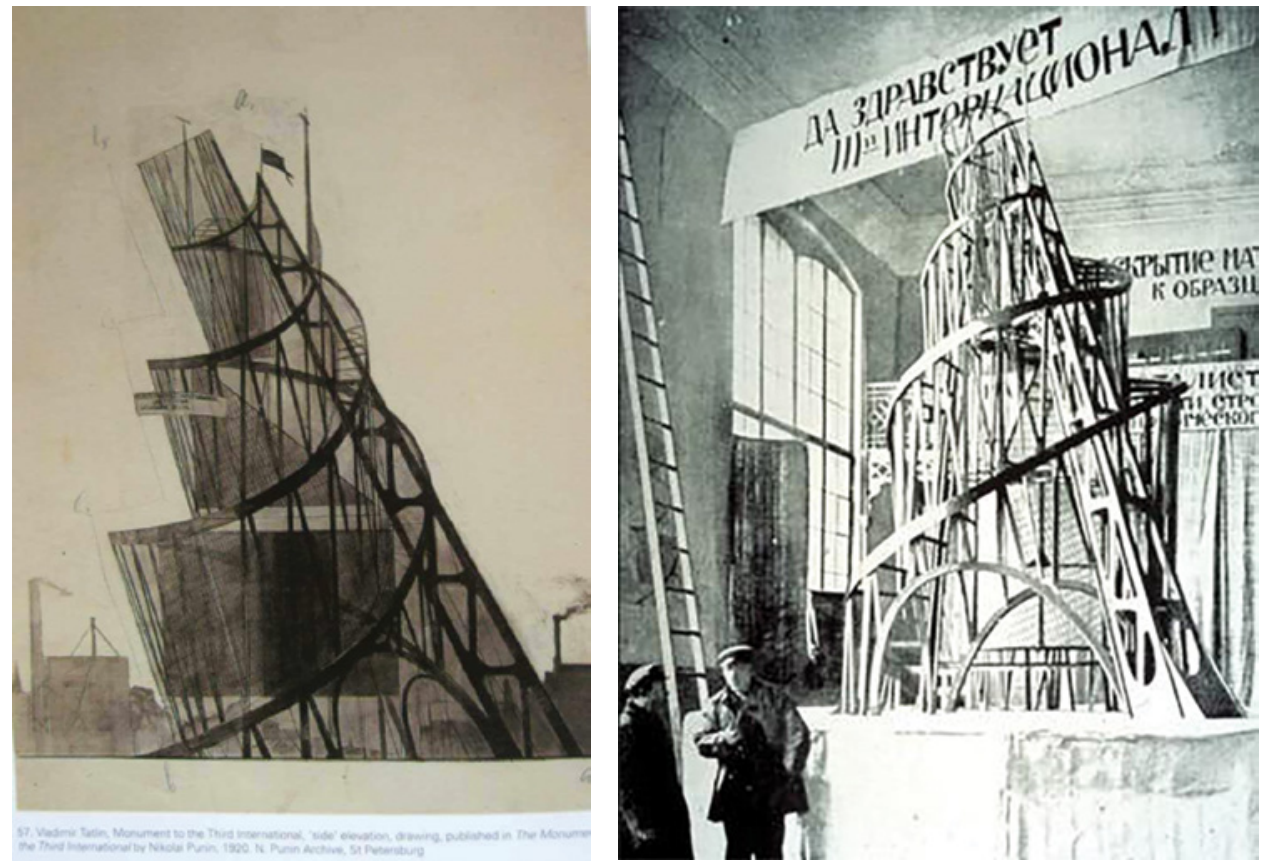

IMAGES 1 AND 2 Vladimir Tatlin, models of the Babel Tower, 1919. 
which can rotate its axes at different speeds and contains a glass cylinder, a glass cone and a glass cube. The design provides space for seminars, conferences and other events. The weight of the spiral-shaped monument was to be over 396.5 metric tons. It can be said that Tatlin was inspired in its design by the Babel Tower.

Tatlin wanted to design a revolutionary monument. This tower was an alternative monument designed for the period that would emphasize constant movement, with futuristic features such as communication technologies, radio-telegraphy, loudspeakers, radio broadcasts and film screenings. Motorcycles and cars would come out of the garage under the wing to distribute announcements. The headlines, slogans and news from the radio station, and other related notifications, would be posted. A huge film screen on the front facade would show political and cultural events around the world. By night, slogans would be projected directly into the sky. Like the Babel Tower, which was also intended to reach the sky, this tower would spread its words there. The constantly moving monument would thus be a giant communication device, just like the Babel Tower.

Tatlin's tower is always compared to the towers of Eiffel and Babylon in art and architecture literature. Eiffel was built for the 1889 Universal Exhibition in Paris. It was thought to be a temporary structure from the beginning. Later, however, when it was to be used as a radio antenna, the tower was protected without being destroyed. The giant 1889 exhibition reveals the supremacy of French imperial power over the world. The display is a symbol of the dominant Eiffel Tower, the center of France's universe and modernity. The universe is literally exhibited under the feet of the tower. The Tower of Babel, as the famous legend tells, is a universal language, and therefore a search for symbol of universal harmony. Likewise Tatlin's tower is dedicated to communism, as a form of utopia dedicated to the union of the world workers and people. It's a utopia machine (a kind of toy).

ARTUN, 2015

The Babel Tower represents a utopia, a realm that cannot be true. The New Babel (Image 3) is an urban utopia by the Dutch artist Constant Nieuwenhuys, who as part of the Russian avant-garde created an updated version of the Babylonian legend for its time.

Constant was a key figure within the post-World War II group of Primitivist painters known as CoBrA. With the dissolution of the CoBrA group in 1951, Constant moved away from painting towards experimental architectural drawing. In 1957, the year prior to the inaugural declaration of the Amsterdam branch of the Situationist International (sI), of which Constant was a founding 


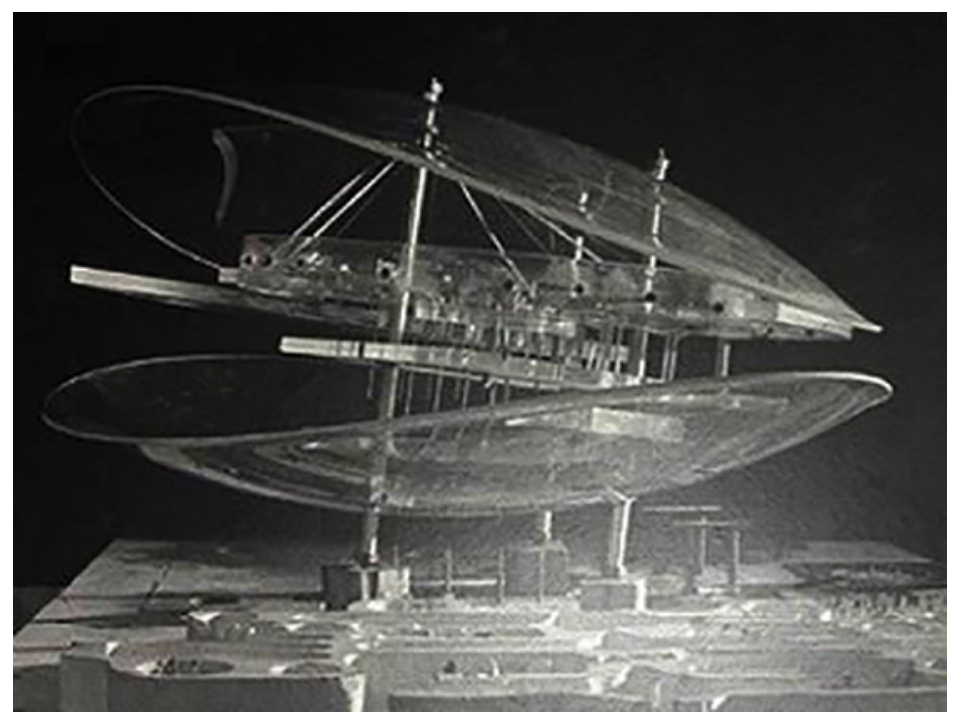

IMAgE 3 Constant Nieuwenhuys, The New Babel (detail), 1956-1974.

and influential member, Debord set out the basic situationist task in the following way:

Our central purpose is the construction of situations, that is, the concrete construction of temporary settings of life and their transformation into a higher, passionate nature. We must develop an intervention directed by the complicated factors of two great components in perpetual interaction: the material setting of life and the behaviors that it incites and that overturn it.

Our prospects for action on the environment lead, in their latest development, to the idea of unitary urbanism. Unitary urbanism first becomes clear in the use of the whole of arts and techniques as means cooperating in an integral composition of the environment.

DEBORD, 1957

This notion of the 'construction of situations' is reformulated a year later by the collective statement of the Amsterdam si in the following manner: 'Only urbanism will be able to become that unitary art that responds to the exigencies of dynamic creativity, the creativity of life.'

At play here in the idea of unitary urbanism are two basic concerns. First, such urbanism involves appropriating the task of the western avant-garde, especially since Dada - namely, an overcoming of art as a limited, 'abstract' 

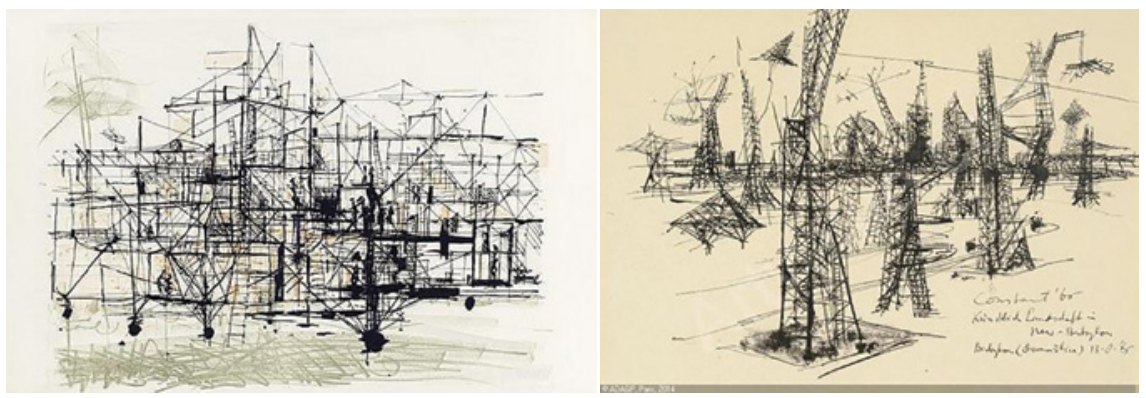

IMAGES 4 AND 5 Constant Nieuwenhuys, New Babylon. Lithograph, $52 \times 79 \mathrm{~cm}$.

(in a Hegelian sense) sphere of praxis in the context of modern material production. According to the task, art is to break free from its abstract particularity and become unitary in the sense of comprehensive or total. Secondly, art must become truly dialectical in the sense of consciously producing or co-producing the human environment for the purpose of realizing the potential richness in varieties of human life. According to this second basic task, unitary urbanism would work to counteract the homogenizing of space by advanced commodity capitalism as proclaimed by Debord in The Society of the Spectacle (Elliott, 2009). Constant and the si may become the main issue of another article. It is necessary to focus here on the transition between post-World War II anti-capitalism and the new (utopian) urbanism by way of Constant's work.

The anti-capitalist work New Babylon (images 4 and 5) by Constant Nieuwenhuys was a prestigious experiment in urbanism. This utopian idea has been visualized with huge models, sketches and other pictures. New Babylon (images 6 and 7 ) is today considered an exemplary expression of the Situationists' take on the city.

The idea was to spend one's life as one wants, as even a person who has the freedom to go where they want, when they want, in the modern world, cannot use this freedom to the greatest extent possible in a world where the dictate of efficacy and efficiency prevails. The New Babel is a nomadic town. The idea of this nomadic town begins with the design of a camp for Constant's Alba gypsies. This is the first model for the New Babel series. In 1953 Constant published a text called For an Architecture of Situation. Constant mentions this utopian design in detail in his essay on New Babel and his concepts. One of the terms that he reveals in this text is the 'utilitarian society'. The term designates all known forms of society, including the modern capitalist and socialist states. It asserts a fundamental reality, the same for all these forms of community life, old and new, namely the exploitation of the human being's capacity for work. 'Utility' 

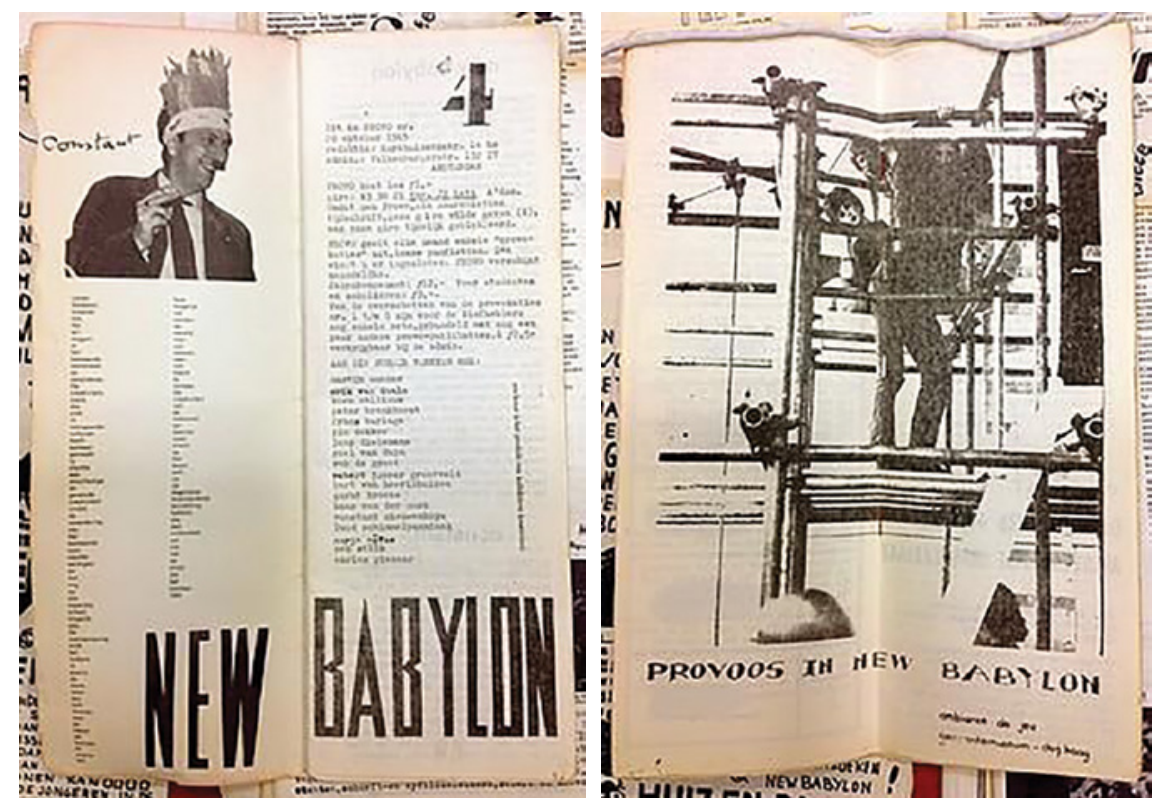

IMAges 6 AND 7 Constant Nieuwenhuys, New Babylon. Documentation (details).

is the principal criterion in appreciating man and his activity. The creative and playing human, Homo Ludens, can only claim his rights on rare occasions. The opposite of a utilitarian society is a ludic society, where the human being, freed by automation from productive work, is at least in a position to develop his creativity. The terms 'class society' and 'classless society' do not express this conflict, or do so imperfectly. But it is clear that a ludic society can only be a classless society. Social justice is no guarantee of freedom, or of creativity, which is the realization of freedom. Freedom depends not only on the social structure, but also on productivity; and the increase in productivity depends on technology. 'Ludic society' in this sense is a new concept (Nieuwenhuys, 1974). The individual of the ludic society is Homo Ludens, described in the same text.

The term 'Homo Ludens' was used for the first time by Johann Huizinga in a book of that title, subtitled 'A Study of the Element of Play in Culture'. In his Foreword, Huizinga speaks of the man who plays in measured terms:

In the course of time we have come to realize that, after all, we are not as reasonable as the eighteenth century, with its worship of reason and its naive optimism, assumed; hence, modern fashion inclines to designate our species as Homo Faber: Man the Maker. But though faber may not be quite so dubious as sapiens, it is, as a name specific to the human being, 
that is even less appropriate, seeing that many animals, too, are makers. There is a third function, however, applicable to both human and animal life, and just as important as reasoning and making - namely, playing. It seems to me that next to Homo Faber, and perhaps on the same level as Homo Sapiens, Homo Ludens, Man the Player, deserves a place in our nomenclature.

HUIZINGA, 1949

This discretion in the use of the term can perhaps be explained by the minor importance utilitarian society gives to play. Homo Ludens has only ever been a rarely manifested modality of Homo sapiens, a condition that, unlike [the condition of] Homo faber, largely goes unnoticed. Huizinga, for whom playing is a flight from 'real' life, does not distance himself in his interpretation from the norms of utilitarian society. And, in his historical analysis of the theme, he quite rightly situates Homo Ludens in the upper echelons of society, more precisely within the propertied leisure class, and not in the labouring masses. However, by separating capacity for work and production, automation has opened the way to a massive increase in the number of Homo Ludens. Huizinga nevertheless had the merit of pointing to the Homo Ludens dormant within each of us. The liberation of man's ludic potential is directly linked to his liberation as a social being (Nieuwenhuys, 1974).

Homo Ludens will meet gaming, adventure and mobility needs first, and will demand a lifestyle that provides the conditions in which he can freely create his life. The main activity of humankind has been the discovery of its natural environment. Homo Ludens will try to recreate this environment, transforming the world according to his new needs. Here, the discovery and the creation of the circle will be intertwined, because Homo Ludens will be trying to discover his own creation, while at the same time also creating the space to explore. So now people will exist within an uninterrupted creation and recreation process that is sustained by a generalized creativity that emerges in every field of activity (Ojalvo, 2012).

The purpose of this design is to move away from all the limiters and norms. The project was also called 'Antitheism of Lie Society'. This is a complete liberation area, reorganizing a world-based experience. It is fluid and dynamic. Babylon's mission is to experience and discover. This freedom in time and space will lead us to a new urbanization. The mobility resulting from the continuous fluctuation of the population (a natural consequence of this new freedom) will create a different relationship between city and settlement. Without a timeline or a fixed shelter, one would not want to encounter a nomadic way of life - unique to a building and an entirely 'built' neighbourhood. 
Let us call this environment New Babylon; and let us add that there is nothing about it, or almost nothing, in the traditional sense of a 'city'. The city is a form of urbanization peculiar to utilitarian society. While it was a place that was guarded against the aggressiveness of the outside world, it became an 'open city' when it became a trade centre; it has since become a production centre with machinery. On the other hand, in all of these different phases, the city is where a fixed population, rooted in a particular way of life, resides. There is no a priori link between people (in New Babylon). The frequency of each person's movements and the ways of following them depend on the decisions he or she will take in the moment and whether they can give up at any moment. Under these circumstances, social mobility is also important. It suggests a kaleidoscopic image of integrity in which momentary and unexpected movements are emphasized: an image that no longer resembles a structure of social life ruled by the utility principle and the behavioural patterns of which are always the same. New Babylon is only the work of the New Babylonians, the product of their culture. For us, it is simply a model. One of the ideals of the avantgardes was to turn everyday life into art. It was an ideal to liberate oneself from alienation and make life a totally creative experience. Russian avant-gardes believed in revolution, because they believed that 'the forms will change the world'. By this means, a new universe would be established, with a new harmony between people and between people and nature.

If we look at today's art world, Anselm Kiefer's description of Babylon is about the collapse of the Babel Tower. The Fertile Crescent (Image 8) depicts the Tower at the moment of dissolution.

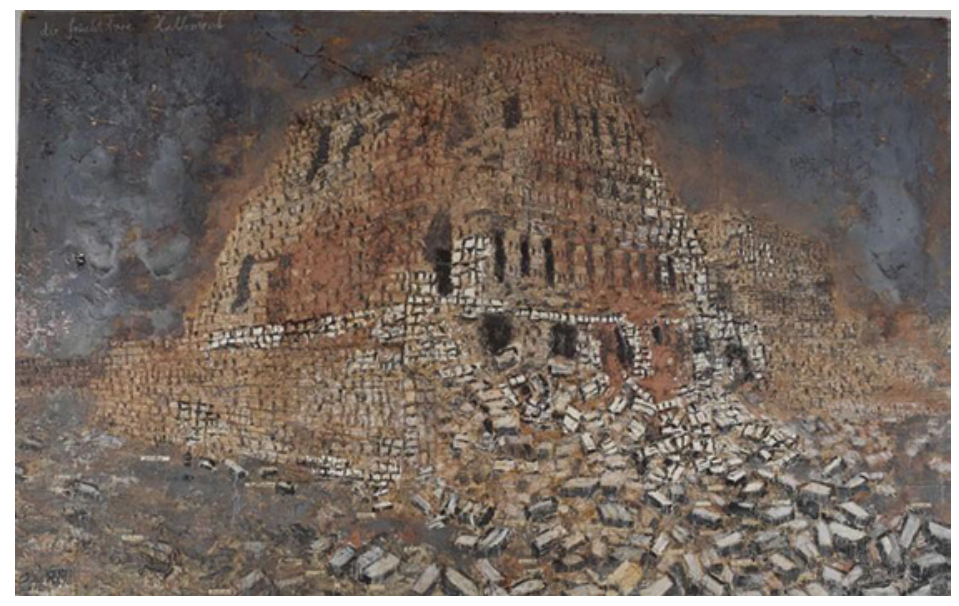

IMAGE 8

Anselm Kiefer, 2009, The Fertile Crescent. Oil on canvas, $460 \times 760 \mathrm{~cm}$. 
The Fertile Crescent - a term first used by the American Orientalist and archaeologist James Henry Breasted - is the region of the Middle East where western and Middle Eastern civilizations originated. It begins in the southeast of Turkey and covers Jordan, Syria and Iraq in the south, extending to the Zagros Mountains of Iran in the east, with a half-moon spread downward (Afşar, 2002). Europeans called it 'Mesopotamia'; Arabs called it 'Al Jazeera'. This region, with both names being used in Ottoman documents, lies roughly between the Dicle and Firat rivers. Anatolia is in the north, Iran in the east, Syria in the west and the Gulf of Basra in the south. The region is known as the cradle of civilization and has a reputation as a fertile zone (Malhut, 2013). More broadly, the Fertile Crescent overlaps the region predominant in the Old Testament Tekvin section; it also includes cultures such as the Babylonian, the Assyrian and the Phoenician, which pre-dated ancient Greek and Roman civilizations. The Fertile Crescent is considered to be the geographical area where agriculture, urbanization, writing, trade, science and animal domestication came into world.

Anselm Kiefer, in his monumental work The Fertile Crescent, shows the collapse of a structure similar to a ziggurat. There is no human life here. However, there are the building blocks of a new culture. So this wreck is not simply the end; it is also the beginning of something new. The things that are there will disappear, but they will emerge again in another form. Even if Kiefer's Babylonian image is optimistic, it does not represent a utopia; it includes the demolition of its representation. Kiefer's epic paintings titled The Fertile Crescent

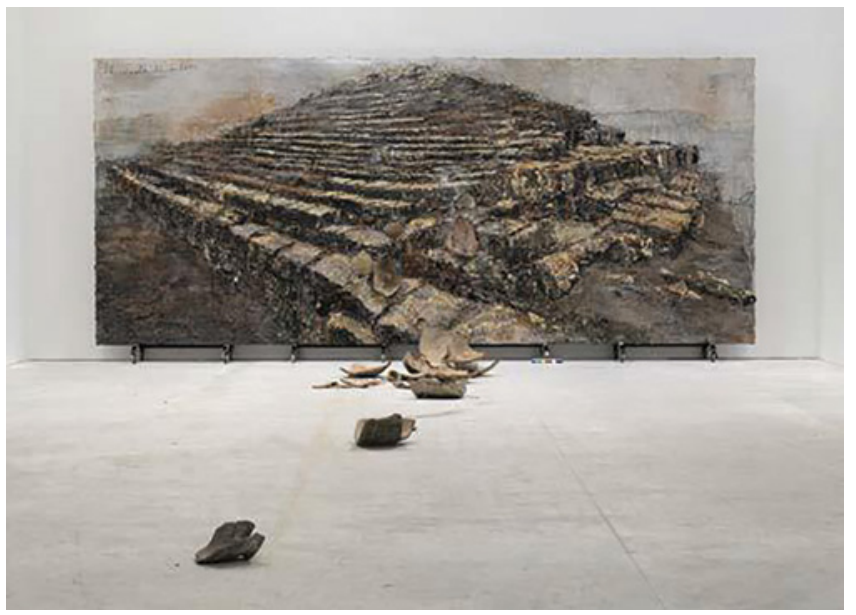

Image 9 Anselm Kiefer, The Fertile Crescent, 2009. Terracotta, acrylic, oil on canvas, $330 \times 760 \times 1300 \mathrm{~cm}$. 
(Image 9) confront the endless cycle of violence, creation and destruction, paradoxes of human history. These efforts are studies that can be read in a multi-layered manner when thinking about destruction and rebirth. The language of the material used plays an important role in the works of Kiefer: the geological sedimentary texture has an important place in his art.

Kiefer bought Barjac's silk factory in the south of France, turning it into his own art factory and linking it to gigantic underground tunnels (Images 10 and 11). This space resembles an apocalyptic place and is fed indirectly from the Babylonian myth. Kiefer interprets the towers in an interview: 'My towers are solid and hard, but they seem about to be overthrown at any moment. This is the catastrophic structure of Babylon. I'm trying to catch the moment of decadence that feels terrifying.'
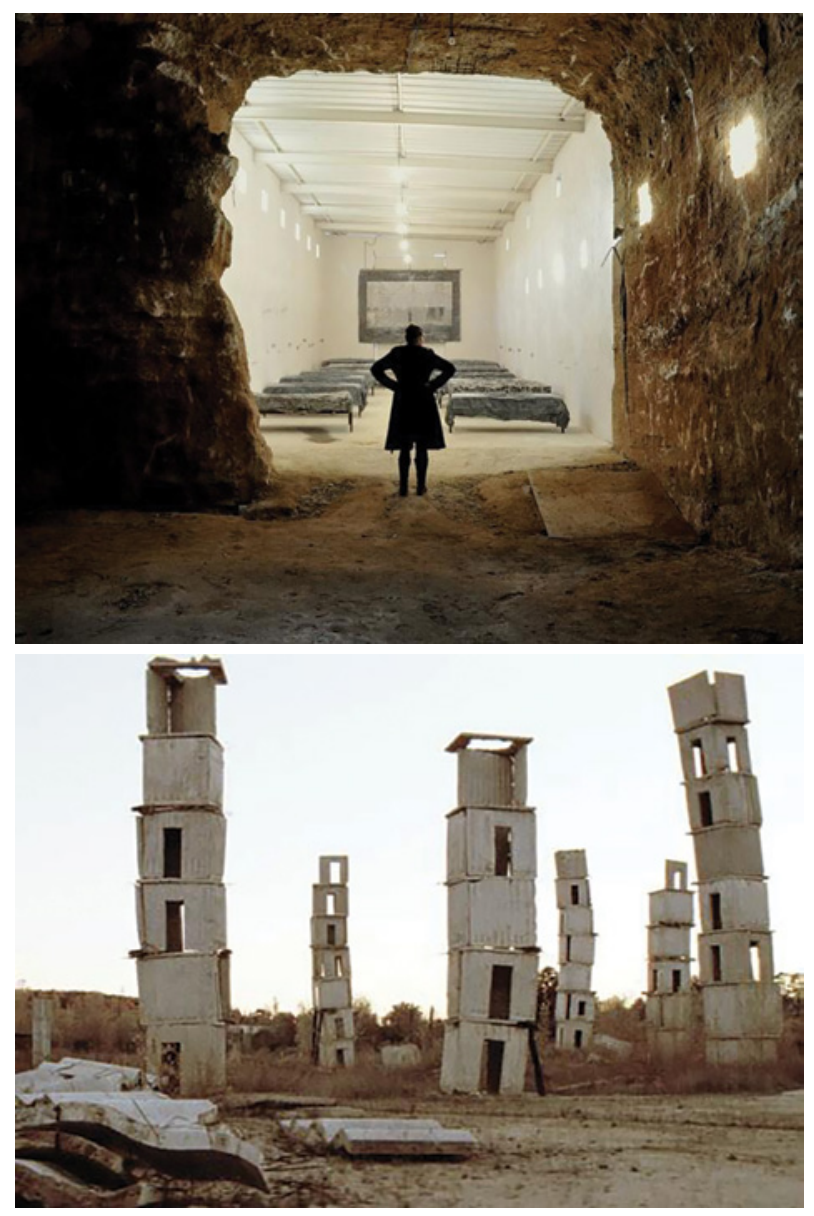

IMAGES 10 AND 11 Anselm Kiefer's studio in Barjac. 

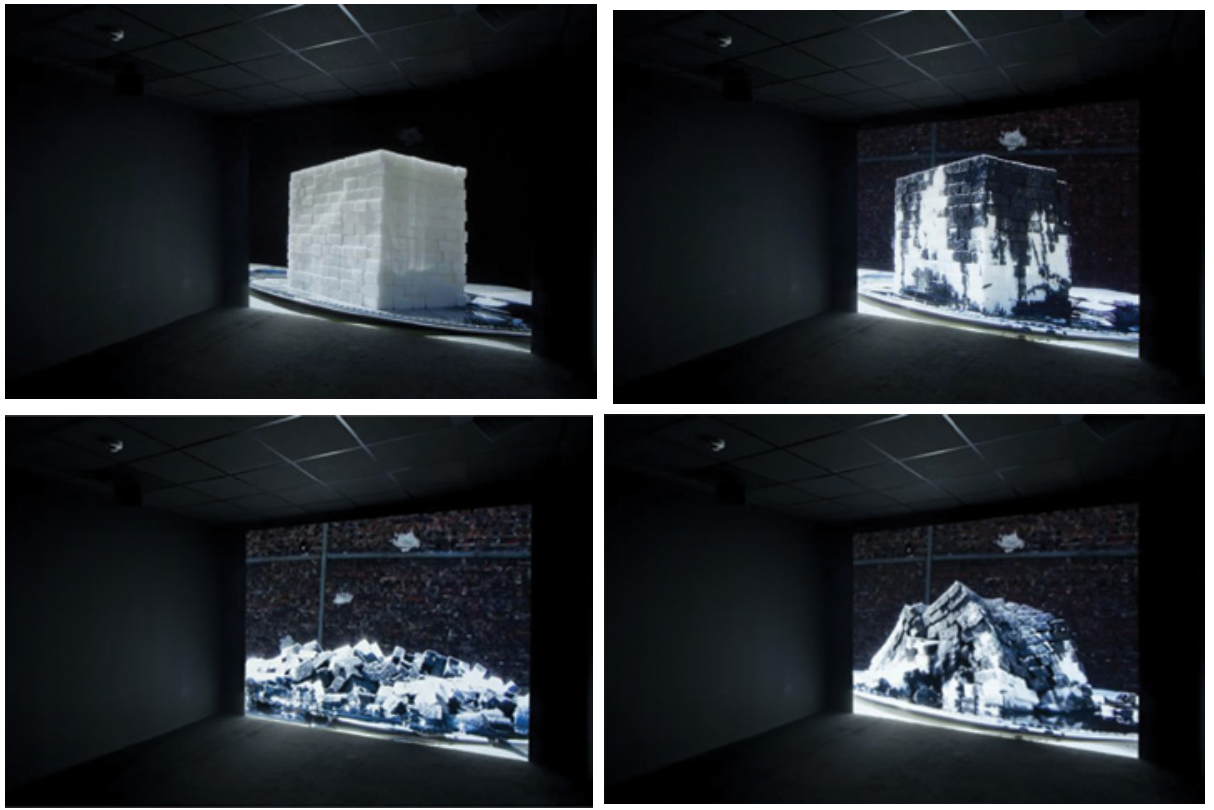

IMAGES 12, 13, 14 AND 15

Kader Attia, Oil and Sugar, 2007. Video projection; colour, sound, 4 min $30 \mathrm{sec}$.

Although not directly related to the Babylonian legend, it is quite possible to establish an analogy with the Babel Tower in Kader Attia's Oil and Sugar (images 12, 13, 14 and 15). The work is a reference to the ideal society designed to be impossible to realize at present, and the ideal divine world order that has lost credibility in utopian quests. Attia's work is symbolically cross-referenced. The Tower is made of sugar cubes, and oil is poured on it; after a while, the materials melt together. Attia establishes oppositions: white and black, solid and liquid, slowly blending into one another, and witnessing to the transformation. In this work, the artist describes a geopolitical realization of geography with a minimalist language. The success of the work is precisely due to this attitude of minimal expression.

The Babel Tower is a universal image, a symbol of both humanity's separation and its unity. It signifies the ironic power of language in human relationships, in that it is a means of both communicating and misunderstanding. Language emerges between humans as a method of interaction and relationship; yet when the language, which is the medium of communication, is ruptured, this separation becomes the symbol of the antagonism. The Babylonian image in contemporary art begins an attempt to encapsulate these contradictions and to demonstrate the destructive powers of language 


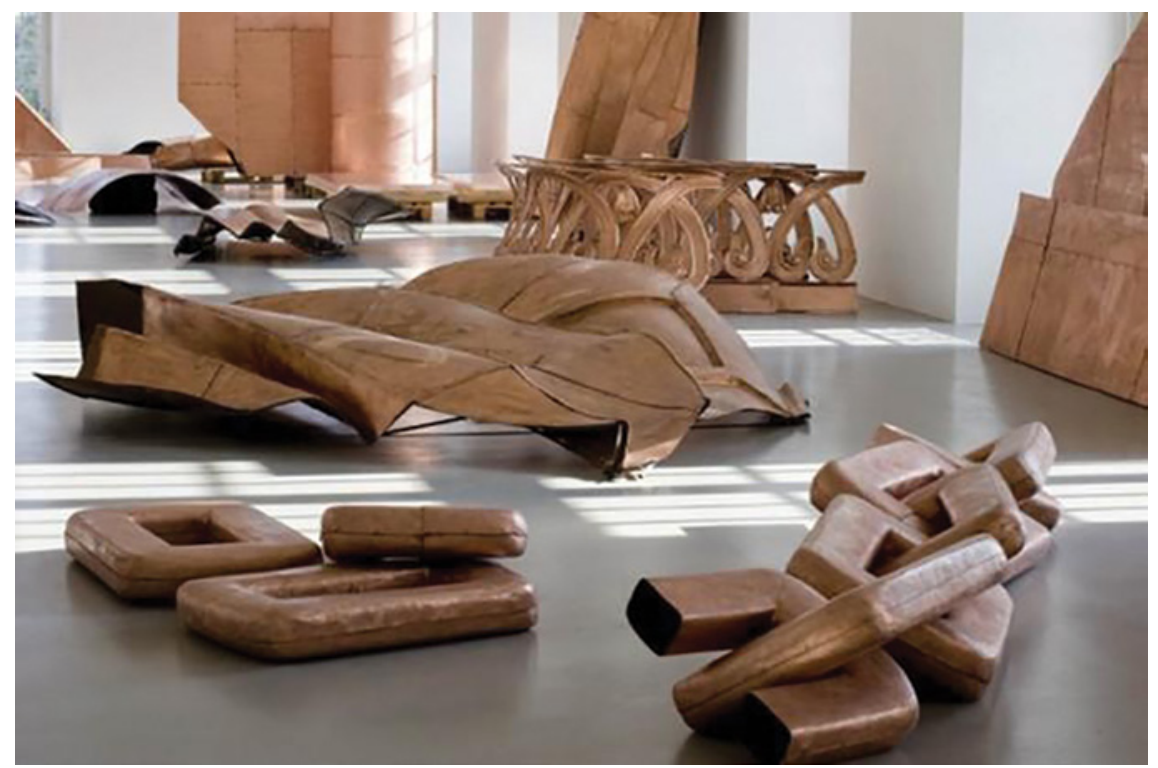

image 16 Danh Vo, We The People (detail), 2011-2014. Courtesy of Galerie Chantal Crousel. Photo: Nils Klinge.

to express differences, dissolutions, incompatibilities, disintegrations and helplessness. A consideration that evaluates Babylon through dystopia or heterotopia can be useful. (This may form another text, as I think it would change the flow of this text.) When evaluated over the monolingual, single-purpose structure that serves the purpose of one goal, Babylon is more a dystopic structure than a reference to a utopian place, for it shows us how close we are. From this point of view, it may be possible to say that the state which evolved after the fall of Babylon is close to the heterotopic structure, which houses the plural in the horizontal plane.

One of the most impressive works on the disintegration of the idea of ideal humanity is Danh Vo's work We The People. It is based on the idea of the reconstruction of the Statue of Liberty. Vo's work of 250 pieces is a replica of the Statue of Liberty (İmage 16); but, unlike the Statue of Liberty, Vo's sculpture is displayed as a demounted piece that does not collect together the parts of the statue. It becomes even more apparent that one is studying how the Statue of Liberty itself is a concrete symbol of an international displacement.

The fragments of Danh Vo's sculpture were designed in Germany, produced in China, supported by an art gallery in France and funded by many art institutions around the world. The pieces of the work were exhibited in more than fifteen countries. The workshop's production process puts a strong emphasis 

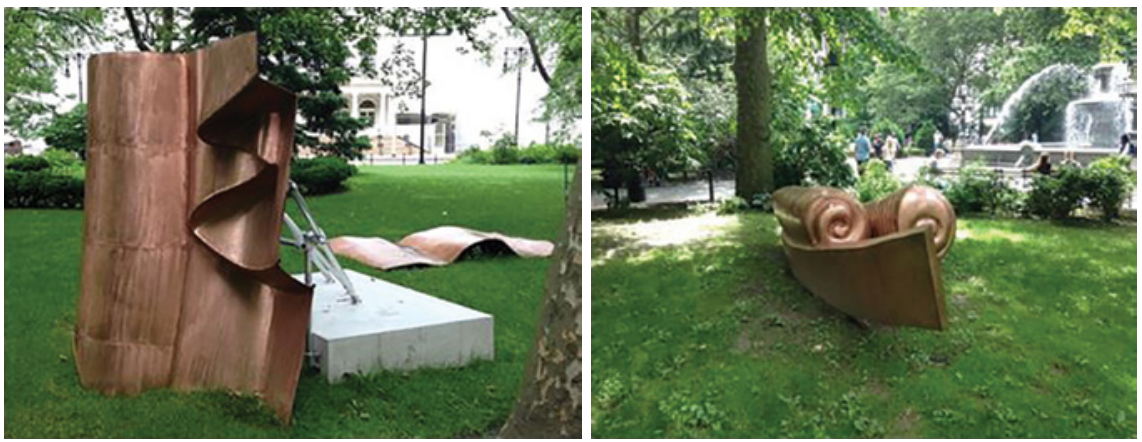

İMAg ES 17 AND 18 Danh Vo, We The People (detail), 2010-2014, City Hall Park.

on today's global bureaucratic structure. Some parts of the work exhibited in Asia, Europe and America were placed in two urban parks on either side of the Brooklyn Bridge. The work was also placed in areas of plants brought from South Asia to Europe by French missionaries in the nineteenth century (Images 17 and 18). This situation strengthens Vo's globalism and international dynamics argument.

Here, Vo's work indirectly establishes an analogy between the Babel Tower and the Statue of Liberty. The fact that both forms of phallic structure would set aside a symbolic reminiscence as gigantic measurements rising up to the chest, where a third element including We the People - it is possible to make a reading. Vo's Statue is fragmented, as in the myth was the Tower of Babel, and the pieces are scattered in different places, thus symbolizing destruction like that of Babylon. Apart from this, when the symbolic presence of the Statue of Liberty is taken into account, it can be said that Danh Vo developed in this work a similar approach to that of Kader Attia's White Cube. Both studies challenge the notion of utopia. The dispersed and multilingual nature of Vo's Statue can be idealized today. As a metaphor of a vertical organization, which is far from our time, Kafka's horizontal organizational analogy 'The Great Wall of China', Constant's playful utopian organization New Babylon, all scare our eyes with the huge dimensions they have been opened to see.

\section{Bibliography}

Afşar, Timuçin (2002), History of Thought I. İstanbul: Bulut Publications, 62.

Artun, Ali (2015), http://www.e-skop.com/skopbulten/rus-avangardi-formlarin-siyaseti -ve-tatlin-kulesi/2748, 12/05/2016.

Baş, Fırat (2005), 'Çevirinin Diyalektiği', Ankara Üniversitiy D TCF Journal, 45: 85-94. 
Debord, Guy (1957), 'Report on the Construction of Situations and on the International Situationist Tendency's Conditions of Organization and Action'. Accessible through https://theanarchistlibrary.org/library/guy-debord-report-on-the-construction-ofsituations.pdf.

Elliott, Brian (2009), 'Debord, Constant, and the Politics of Situationist Urbanism'. Philosophy Faculty Publications and Presentations. Paper 22-25.

Malhut, Mustafa (2013), 'Power Struggle of British and German on Mesopotamia', History School, Sayı XIV: 147-161.

Nieuwenhuys, Constant (1974), exhibition catalogue published by the Haags Gemeentenmuseum, The Hague, 1974. http://www.notbored.org/new-babylon.html 09/01/2017.

Nieuwenhuys, Constant, Çeviri: Roysi Ojalvo, 4/10/2012, http://www.e-skop.com/skop bulten/pasajlar-yeni-babil-bir-kulturun-ana-hatlari/896, 08/04/2016. 